\title{
Pet- and pollen-induced upper airway symptoms in farmers and in nonfarmers
}

\author{
H.O. Koskela*, K.K. livanainen\#, S.T. Remes ${ }^{\Uparrow}$, J. Pekkanen\#
}

Pet- and pollen-induced upper airway symptoms in farmers and in nonfarmers. H.O. Koskela, K.K. Iivanainen, S.T. Remes, J. Pekkanen. (C) ERS Journals Ltd 2003. ABSTRACT: The effect of farming on the risk of upper airway symptoms is not clear. In this cross-sectional, population-based study, 198 female farmers, 50 nonfarmers living on a farm, and 218 nonfarmers not living on a farm, filled in a symptom questionnaire and underwent skin-prick testing with common and agricultural allergens. In the logistic regression analysis, the latter group served as a control. Several adjustments were made, including childhood farming environment.

Current farming was found to decrease the risks of pet- and pollen-induced upper airway symptoms, dose-dependently with the intensity and duration of animal husbandry. Including skin-test positivity to pets in the regression models did not affect the negative association between farming and pet-induced symptoms. In contrast, animal husbandry increased the risk of farm work-induced upper airway symptoms.

Animal husbandry often induces work-related upper airway symptoms. However, the present study among female adults suggests that it may also decrease the risk of pet- and pollen-induced upper airway symptoms.

Eur Respir J 2003; 22: 135-140.
*Dept of Respiratory Medicine, Kuopio University Hospital, ${ }^{\#}$ Unit of Environmental Epidemiology, National Public Health Institute, "Dept of Paediatrics, Kuopio University Hospital and Unit of Environmental Epidemiology, National Public Health Institute, Kuopio, Finland.

Correspondence: H.O. Koskela, Dept of Respiratory Medicine, Kuopio University Hospital, PL 1777, 70210 Kuopio, Finland.

Fax: 35817172683

E-mail: heikki.koskela@kuh.fi

Keywords: Epidemiology, farmers, rhinitis, skin-prick tests

Received: November 262002

Accepted after revision: February 102003
Several studies have shown that growing up on a farm decreases the risk of allergic and respiratory symptoms, such as hay fever, wheezing and asthma, in children [1-4]. This effect may last up to adulthood, at least for upper airway symptoms (UAS) [5-7]. The decreased risk afforded by a farming environment may be due to a high level of environmental exposure to endotoxin and other bacterial wall components in early childhood. This would enhance the maturation of T-helper (Th) cells to Th1-type cells, which downregulate immunoglobulin (Ig)E responses [8].

During adulthood, farming seems to increase the risk of lower airway symptoms. Several studies have confirmed that the prevalence of cough, phlegm production, shortness of breath and organic dust toxic syndrome (ODTS) are higher in farmers than in the nonfarming population [9-14]. The situation with UAS is less clear. It seems that nasal irritation during work is common among farmers but the prevalence of nasal allergies may be even lower in farmers, compared with the general population [14-16].

Thus, it seems possible that like in childhood, farming during adulthood could also have protective effects on allergic UAS. However, as farm work itself commonly induces UAS, these protective effects can be difficult to detect if only the overall prevalence of UAS is compared between farmers and nonfarmers. It was therefore hypothesised that UAS, which are induced by common allergens, may be less prevalent in farmers than in nonfarmers. In the present study, the authors assessed the prevalence of upper and lower airways symptoms in female farmers mainly working with dairy cattle. In Finland, females have traditionally taken care of the cattle. The inducers of UAS were assessed in detail. By performing skin-prick tests, the authors were able to investigate the role of IgE-dependent mechanisms in the development of these symptoms. In this study, the effect of the childhood farming environment was also taken into account.

\section{Materials and methods}

\section{Study population}

This study was carried out in the 17 municipalities of the former Kuopio county. The study area consisted of mostly rural areas with a few small towns. The present study is connected to a study of the effect of a farming environment on children, and thus the farmers and nonfarmers were recruited in the following way. Four-hundred and sixty-two children aged 6-13 yrs whose fathers were farmers and an equal number of randomly selected nonfarmers' children were drawn from the Central Population Registry. Only one child per family was selected. The population of the present study consists of the mothers of these children. For practical reasons, the examination of the mothers was started only after the children of the first two municipalities had already been studied. Therefore, only 676 of the 924 mothers were invited to join the study.

Informed written consent was obtained from every participant and the study was approved by the Ethical Committee for Human Research of Kuopio University Hospital, Finland.

\section{Study design}

The mothers and their children were asked to visit a nearby school where the skin-prick tests were performed and the 
questionnaires were given. The mothers filled in the questionnaire at home and then mailed it to the investigators.

\section{Skin-prick tests}

The testing was carried out in the winter of 2001, to avoid the influence of pollen season, by a single fieldworker, according to the International Study of Asthma and Allergies in Childhood protocol [17].

A panel of 10 ALK (Allergologiska Laboratorium, Copenhagen, Denmark) allergens was used. Seven of the allergens were standardised (birch, timothy grass and mugwort pollens, cat, $\mathrm{dog}$, horse dander and house dust mite (Dermatophagoides pteronyssinus)) and three were not (bovine dander, cockroach and storage mite (Lepidoglyphus destructor)). The concentration of the standardised extracts was 10 histamine-equivalent pricks; the concentration of the nonstandardised extracts was 100 biological units (for storage mite) and 1:100 w/v (cow epithelial dander and cockroach). Histamine dihydrochloride $\left(10 \mathrm{mg} \cdot \mathrm{mL}^{-1}\right)$ and glycerol $(50 \%)$ were used as positive and negative controls, respectively. The same batch of each solution was used throughout the study. For a test to be included in the final analyses, the reaction to the positive control had to be $\geqslant 3 \mathrm{~mm}$ and the reaction to the negative control had to be $\leqslant 1 \mathrm{~mm}$

\section{Questionnaire}

Diagnoses and symptoms of respiratory diseases were assessed in detail using a self-administered questionnaire. The presence of other current or previous illnesses was also established. Potential explanatory and confounding factors related to the development of allergic diseases were included. Information from the children's questionnaire, which included occupational questions aimed at the farmers, was also utilised.

\section{Definitions}

Skin-test positivity. Equal or larger than a 3-mm skin-prick test reaction to any of the allergens.

Organic dust toxic syndrome. Fever or chills associated with work exposure, which did not appear to be caused by a common cold. These symptoms had to vanish within 3 days from the end of the exposure [18].

Chronic bronchitis. Phlegm production on most days for $\geqslant 3$ months $\cdot \mathrm{yr}^{-1}$. The subjects with a doctor's diagnosis of asthma were excluded [12].

Current wheezing. Wheezing breath sound during the previous 12 months.

Use of asthma medication. Use within the previous 12 months.

Chronic rhinitis. Symptoms of rhinitis, which were chronic or appeared repeatedly, and were not related to acute upper airway infection.

Chronic conjunctivitis. Eye irritation, which was chronic, or appeared repeatedly, and was not related to acute upper airway infection

Pet-induced upper airway symptoms. If a subject had reported chronic rhinitis and/or chronic conjunctivitis, they were asked about the triggers of these, and dogs and cats were included in the list of possible triggers.

Pollen-induced upper airway symptoms. As pet-induced UAS, but for flowers or pollens.

Farm work-induced upper airway symptoms. Chronic rhinitis and/or chronic conjunctivitis when participating in farm work.

\section{Statistical analysis}

Prevalences of the various categorical characteristics were compared by the Chi-squared test between the groups and analysis of variance was used to compare the groups with respect to continuous variables. Association of current farming with prevalence of symptoms was analysed using multivariate logistic regression models and the following potential confounders were considered: childhood farming environment, number of older siblings, parental atopy (history of asthma, hay fever or eczema in either parent), early childhood daycare attendance, having had pets in childhood, passive smoking during childhood, having a cat or dog mostly indoors currently, being a current/ex-lever-smoker, age and length of education.

If adjusting for the potential confounder changed the odds ratio (OR) of being a farmer by $>10 \%$, the confounder was included in the final model. According to these analyses, the following confounding variables were recognised for different symptoms. 1) Childhood farming environment for ODTS. 2) Childhood farming environment, age and having had pets in childhood for wheezing. 3) Having a cat or dog mostly indoors currently for chronic conjunctivitis. 4) Childhood farming environment for pollen-induced UAS. 5) Childhood farming environment, having had pets in childhood and parental atopy for pet-induced UAS. Skin-test positivity was not included as a confounding variable as it is potentially an intermediate variable between farming exposure and symptoms.

The interaction effect of childhood farming environment and current farming on the symptoms was tested by creating a new variable (the interaction variable) by multiplying the childhood farming exposure (1 or 2) with adulthood farming exposure (1 or 2$)$. This variable was then included in the regression models in addition to the childhood and adulthood farming exposures. Association of the symptoms with skintest positivity was analysed using logistic regression. Results are expressed as means and $95 \%$ confidence intervals (CI).

\section{Results}

\section{Population}

Of the 676 females invited to join the study, $511(75.6 \%)$ participated in skin-prick testing and $466(68.9 \%)$ returned the questionnaire. The analysis of the present study is based mainly on these 466 females. Of them, 198 lived on a farm and participated in farm work, 50 lived on a farm but did not participate in farm work and 218 neither lived on a farm nor participated in farm work (table 1). The analysis of the association between the various symptoms and the skin-prick test results is based on the females who both returned the questionnaire and participated in skin-prick testing. Of them, 28 with a positive reaction to the negative control and four with a negative reaction to histamine were excluded from the analyses. Acceptable skin-prick test results and questionnaires were obtained from 433 females. 
Table 1.-Basic characteristics of the subjects

\begin{tabular}{|c|c|c|c|c|}
\hline & $\begin{array}{l}\text { Nonfarmers not } \\
\text { living on a farm }\end{array}$ & $\begin{array}{c}\text { Nonfarmers } \\
\text { living on a farm }\end{array}$ & Farmers & p-value \\
\hline Subjects $n$ & 218 & 50 & 198 & \\
\hline Age yrs & $39.3(38.6-40.1)$ & $41.4(39.7-43.2)$ & $41.3(40.5-42.1)$ & 0.001 \\
\hline $\mathrm{BMI} \mathrm{kg} \cdot \mathrm{m}^{-2}$ & $25.2(24.6-25.7)$ & $25.5(24.5-26.5)$ & $25.6(25.0-26.3)$ & 0.55 \\
\hline Skin-test positivity & 36 & 35 & 36 & 0.97 \\
\hline Smoking ever & 34 & 16 & 20 & 0.002 \\
\hline Length of education yrs & $12.9(12.5-13.3)$ & $13.8(13.0-14.5)$ & $13.0(12.6-13.4)$ & 0.13 \\
\hline Having cats or dogs indoors currently & 34 & 46 & 57 & $<0.001$ \\
\hline Parenteral atopy & 41 & 34 & 40 & 0.68 \\
\hline Number of older siblings & $1.7(1.5-1.9)$ & $1.7(1.1-2.2)$ & $2.0(1.7-2.3)$ & 0.30 \\
\hline Childhood farming environment & 48 & 62 & 71 & $<0.001$ \\
\hline Pets during childhood & 72 & 65 & 81 & 0.04 \\
\hline Passive smoking during childhood & 69 & 58 & 56 & 0.02 \\
\hline Allergic dermatitis during childhood & 22 & 28 & 22 & 0.64 \\
\hline Childhood daycare attendance & 3.2 & 2.0 & 1.0 & 0.30 \\
\hline
\end{tabular}

Data are presented as mean $(95 \%$ confidence interval) or per cent, unless otherwise stated. The continuous variables were compared by analysis of variance between the groups. The categorical variables were compared between groups using the Chi-squared test. BMI: body mass index.

Table 2. - Prevalence of the symptoms

\begin{tabular}{|c|c|c|c|c|c|}
\hline Symptom & $\begin{array}{l}\text { Nonfarmers not } \\
\text { living on a farm }\end{array}$ & $\begin{array}{c}\text { Nonfarmers } \\
\text { living on a farm }\end{array}$ & Farmers & $\begin{array}{l}\text { Being a } \\
\text { farmer }\end{array}$ & $\begin{array}{l}\text { Only living } \\
\text { on a farm }\end{array}$ \\
\hline Subjects $n$ & 218 & 50 & 198 & & \\
\hline ODTS & 1.8 & 4.0 & 6.6 & $4.3(1.3-14)$ & $2.4(0.4-14)$ \\
\hline Chronic bronchitis & 12 & 10 & 11 & $0.9(0.5-1.7)$ & $0.8(0.3-2.3)$ \\
\hline Current wheezing & 11 & 6.0 & 10 & $1.2(0.6-2.4)$ & $0.6(0.2-2.3)$ \\
\hline Doctor's diagnosis of asthma & 6.0 & 4.0 & 8.6 & $1.5(0.7-3.1)$ & $0.6(0.1-3.0)$ \\
\hline Use of asthma medication & 4.2 & 0 & 7.6 & $1.9(0.8-4.4)$ & + \\
\hline Chronic rhinitis & 38 & 40 & 37 & $0.9(0.6-1.4)$ & $1.1(0.6-2.0)$ \\
\hline Chronic conjunctivitis & 40 & 42 & 31 & $0.8(0.5-1.2)$ & $1.2(0.6-2.2)$ \\
\hline Pollen-induced UAS & 24 & 22 & 15 & $0.6(0.4-1.0)$ & $0.96(0.5-2.0)$ \\
\hline Pet-induced UAS & 16 & 22 & 5.1 & $0.3(0.1-0.7)$ & $1.8(0.8-3.9)$ \\
\hline Farm work-induced UAS & & & 28 & & \\
\hline
\end{tabular}

Data are presented as per cent or adjusted odds ratio ( $95 \%$ confidence interval), unless otherwise stated. ODTS: organic dust toxic syndrome; UAS: upper airway symptoms. " : comparing farmers with nonfarmers not living on a farm; ${ }^{\natural}$ : comparing nonfarmers living on a farm with nonfarmers not living on a farm; ${ }^{+}$: odds ratios could not be calculated since none of the nonfarmers living on a farm used asthma medication.

\section{Symptoms}

Farming was associated with decreased risks of pollen- and pet-induced UAS (table 2). However, $28 \%$ of the farmers reported farm work-induced UAS. Farming was also associated with an increased risk of ODTS and an increased prevalence of use of asthma medication, though the latter did not reach statistical significance. The risks of all symptoms were similar in those females who lived on a farm but did not participate in farm work compared with the nonfarmers who did not live on a farm.

Skin-test positivity tended to increase the risk of all symptoms (table 3). Strong associations were found between specific UAS and respective skin-test results, showing the high validity of these symptoms to demonstrate specific allergies (table 4). As mentioned, skin-test positivity was not included as a confounding variable in the analysis of the risk of various symptoms between farmers and nonfarmers, since it is potentially an intermediate variable between farming exposure and symptoms. However, including skin-test results in the regression models had little effect on the negative association of being a farmer and pet-induced UAS. With respect to dog-induced UAS, the OR of being a farmer was 0.24 (CI $0.08-0.65$ ) without including the skin-test response to dog in the model, and $0.22(0.09-0.72)$ with the skin-test result included. With respect to cat-induced UAS, the OR of being a farmer was
$0.16(0.05-0.57)$ without including the skin-test response to cat in the model, and $0.16(0.04-0.62)$ with the skin-test result included. With respect to pollen-induced UAS, inclusion of the positive skin-test reaction to any of the pollens (birch, timothy or mugwort) changed the OR of being a farmer from $0.61(0.36-1.00)$ to $0.69(0.38-1.30)$.

There was an inverse dose/response relationship between the prevalence of pollen- and pet-induced UAS and the intensity and duration of animal husbandry (table 5). In contrast, the risk of farm work-induced UAS significantly

Table 3. - Association of the symptoms with skin-test positivity ( $\geqslant 3 \mathrm{~mm}$ or larger skin weal reaction to any of the tested allergens)

\begin{tabular}{ll}
\hline Symptom & OR $(95 \% \mathrm{CI})$ \\
\hline ODTS & $1.6(0.61-4.3)$ \\
Chronic bronchitis & $1.5(0.82-2.8)$ \\
Current wheezing & $1.6(0.80-3.1)$ \\
Doctor's diagnosis of asthma & $2.8(1.3-6.2)$ \\
Use of asthma medication & $2.3(0.92-5.6)$ \\
Chronic rhinitis & $2.8(1.9-4.2)$ \\
Chronic conjunctivitis & $2.7(1.8-4.0)$ \\
\hline
\end{tabular}

OR: odds ratio; CI: confidence interval; ODTS: organic dust toxic syndrome. 
Table 4. - Association of the specific upper airway symptoms (UAS) with respective skin-test results

\begin{tabular}{lc}
\hline Symptom & OR $(95 \%$ CI $)$ \\
\hline Pollen-induced UAS & $14.0(7.6-27.0)$ for a positive \\
& skin-test result to at least \\
& one of birch, timothy or mugwort \\
Cat-induced UAS & $27(12-61)$ for a positive \\
& skin-test result to cat \\
Dog-induced UAS & $12.0(5.8-27.0)$ for a positive \\
& skin-test result to dog \\
Farm work-induced UAS & 5.1 (1.6-17.0) for a positive \\
& skin-test result to bovine dander \\
\hline
\end{tabular}

OR: odds ratio; CI: confidence interval. "\#: farm work-induced UAS analysis was confined to the farmers only; ${ }^{\circ}$ : apart from bovine dander, none of the other tested allergens was significantly associated with farm work-induced UAS.

increased with the intensity and duration of animal husbandry. The risk of pollen- and pet-induced UAS was lowest among the females who had both childhood and adulthood farming exposure (table 6). The "interaction variable" was statistically significantly $(\mathrm{p}=0.036)$ associated with pet-induced UAS, but not with pollen-induced UAS. Among the farmers, the prevalence of pollen-induced UAS was higher in those with work-induced UAS compared with those without them (32 versus $7.7 \%, \mathrm{p}<0.001$ ) and the tendency was the same with respect to pet-induced UAS (8.9 versus $3.5 \%, \mathrm{p}=0.12$ ).

\section{Discussion}

This study shows that in females, intensive and longstanding animal husbandry is associated with a decreased risk of pet- and pollen-induced UAS and with an increased risk of farm work-induced UAS. These findings are in agreement with previous studies pointing to a low prevalence of UAS, which are thought to be allergic [14-16], and to a high prevalence of farm work-induced UAS in animal farmers [15, $16,19,20]$. This study extends the findings of previous studies by confirming the allergic nature of these symptoms, since skin tests were also carried out. Apart from ODTS, farming
Table 6. - Risk of pollen- and pet-induced upper airway symptoms (UAS) with respect to childhood and current farming exposure

\begin{tabular}{lccc}
\hline $\begin{array}{l}\text { Living on a farm } \\
\text { in childhood/ } \\
\text { current farm work }\end{array}$ & $\mathrm{n}^{\#}$ & \multicolumn{2}{c}{ Adjusted OR $(95 \% \mathrm{CI})$} \\
\cline { 3 - 4 } & & $\begin{array}{c}\text { Pollen-induced } \\
\text { UAS }\end{array}$ & $\begin{array}{c}\text { Pet-induced } \\
\text { UAS }\end{array}$ \\
\hline No/no & 113 & 1.00 & 1.00 \\
No/yes & 58 & $0.68(0.31-1.50)$ & $0.66(0.26-1.70)$ \\
Yes/no & 105 & $0.81(0.43-1.50)$ & $0.96(0.41-2.20)$ \\
Yes/yes & 140 & $0.43(0.22-0.82)$ & $0.09(0.02-0.43)$ \\
\hline
\end{tabular}

OR: odds ratio; CI: confidence interval. ${ }^{\#}$ : those 50 females who lived on a farm but did not participate in farm work are omitted from analysis.

did not significantly affect the risk of lower airway symptoms in the present study.

Although there was a clear dose-dependency in the negative association between pet- and pollen-induced UAS and animal husbandry, as well as in the positive association between work-related UAS and animal husbandry, the authors can only speculate about the potential causal relationships. For example, it could be assumed that the farmers with workrelated symptoms may simply ignore pet- or pollen-induced symptoms, perhaps due to their lesser significance on their occupation. However, this explanation seems unlikely, since those with work-induced UAS tended to report pet- and pollen-induced UAS more often than those without workinduced UAS. This finding also makes unlikely the explanation that work-induced symptoms per se would have some kind of protective effect on allergic symptoms in the upper airways. Therefore, it seems more likely that there are factors in animal husbandry that irritate the upper airways and factors that decrease the sensitivity to common allergens like pets and pollens.

Farmers have potential exposures to a very wide variety of irritant agents, including inorganic dust from the soil, organic dust containing microorganisms and animal-derived material, mycotoxins, decomposition gases, etc. [21]. In the present farmer population, at least part of the work-induced UAS could be explained by sensitisation to bovine allergens. In previous studies regarding farmers, work-induced UAS have

Table 5.-Adjusted odds ratios (95\% confidence interval) for upper airway symptoms (UAS) with respect to farming characteristics

\begin{tabular}{|c|c|c|c|c|}
\hline Farming characteristic & $\mathrm{n}$ & Pollen-induced UAS & Pet-induced UAS & Farm work-induced UAS \\
\hline No farming & 268 & 1 & 1 & \\
\hline Part-time farming & 74 & $1.0(0.6-1.9)$ & $0.4(0.2-1.1)$ & 1 \\
\hline Full-time farming & 124 & $0.4(0.2-0.8)$ & $0.2(0.1-0.6)$ & $1.9(1.0-3.8)$ \\
\hline \multicolumn{5}{|l|}{ Type of farm } \\
\hline No farming & 268 & 1 & 1 & \\
\hline Dairy farming & 109 & $0.5(0.3-0.9)$ & $0.3(0.1-0.8)$ & $10.0(2.9-35.0)$ \\
\hline Other animal husbandry & 29 & $0.6(0.2-1.8)$ & \# & $7.2(1.7-30.0)$ \\
\hline Crop farming & 50 & $0.7(0.3-1.5)$ & $0.2(0.1-1.0)$ & 1 \\
\hline \multicolumn{5}{|c|}{ Visits in cow shed during the last 12 months } \\
\hline No visits & 194 & 1 & 1 & 1 \\
\hline Once a day or less & 177 & $0.9(0.5-1.4)$ & $0.6(0.3-1.1)$ & $2.1(0.4-10.0)$ \\
\hline More than once daily & 95 & $0.7(0.4-1.4)$ & $0.2(0.1-0.7)$ & $5.2(1.1-24.0)$ \\
\hline \multicolumn{5}{|c|}{ Duration of work with animals } \\
\hline Not at all & 231 & 1 & 1 & 1 \\
\hline$<5 \mathrm{yrs}$ & 45 & $1.0(0.5-2.1)$ & $1.1(0.4-2.8)$ & $2.3(0.3-15.0)$ \\
\hline $5-15$ yrs & 67 & $0.6(0.3-1.3)$ & $1.1(0.5-2.4)$ & $5.3(1.1-26.0)$ \\
\hline$>15 \mathrm{yrs}$ & 96 & $0.4(0.2-0.8)$ & $0.4(0.1-1.1)$ & $8.5(1.9-39.0)$ \\
\hline
\end{tabular}

${ }^{\#}$ : none of the 29 farmers working with animals but not participating in dairy farming complained of pet-induced UAS; ${ }^{\uparrow}$ : farm work-induced UAS analysis was confined to the 198 farmers only. 
been shown to correlate with high exposure to dust, endotoxin and fungal spores $[19,20]$. Therefore, it seems probable that work-induced UAS in farmers result from exposure to many different inducers.

What mechanism could then explain the "protective effect" of adulthood farming on pet- and pollen-induced UAS? In children, the farming environment is thought to decrease the risk of allergic disorders by enhancing the maturation of $\mathrm{Th}$ cells to Th1-type cells, which downregulate IgE responses, thereby decreasing the risk of IgE-mediated sensitisation to allergens [8]. However, this programming of T-cells usually occurs before the age of 5 yrs [22]. Therefore, it is unlikely that the present findings in adults could be explained by the same mechanisms. This view is also supported by the following findings. First, including skin-test reactions to dog or cat in the regression models had no effect on the negative association between farming- and pet-induced UAS. Second, the overall prevalence of skin-test positivity was not different between the groups. Therefore, the "protective factor" of adulthood farming barely acts by affecting the T-cell maturation. It seems more possible that this factor could have or induce some kind of nonspecific anti-inflammatory activity on upper airways, making an individual less sensitive to common stimuli, regardless of the allergic status of the individual.

The dose-dependent negative association between the intensity and duration of animal husbandry and allergic UAS suggests that the possible protective factor in the farming environment may be directly derived from animals. Studies in children also suggest that contact with farm animals seems to be an essential part of the "protective farming effect" [23]. Although the present study revealed the importance of bovine allergens in farm work-induced UAS, the authors have no evidence that bovine dander is the unknown protective factor.

The protective effect of current farming on pet symptoms was stronger in the farmers who had also spent their childhood on a farm. As the protective farming effect during childhood is thought to act by enhancing the maturation of Th cells to Th1-type cells [8], it may be argued that the Th1dominated immune response pattern makes an individual prone to the protective effects of farming during adulthood. If this is the case, early childhood T-cell programming has very long-term consequences, all of which are not measurable with skin-prick tests.

In this kind of cross-sectional study there is always a possibility that selection bias has affected the results. It could be thought that subjects with pet- or pollen-induced UAS may decide not to become a farmer or that subjects with such symptoms may quit farming more probably than subjects without these symptoms. Although these possibilities cannot be definitively ruled out, there is a finding that argues against the selection at the stage when females have chosen their occupation. The risk of pet- and pollen-induced UAS was virtually the same in females who had spent their childhood on a farm but did not work on a farm currently, compared with females who had not spent their childhood on a farm and did not work on a farm currently. If there was an allergic symptoms-related tendency to selection when choosing the occupation, a greater risk of allergic UAS in the former group would be expected. The authors feel that the latter means of selection, namely that the pet- or pollen-induced UAS may force the females to quit farming, is also not very probable; it seems very unreasonable to assume that pet- or polleninduced UAS would be important enough to cause farmers to make such an major economical decision like changing an occupation. This argument is also supported by a Swedish follow-up study, which showed that farmers change their occupation less often than those in other occupations, especially due to health reasons [24].

Apart from the increased risk of ODTS in farmers, farming was not significantly associated with other lower airway symptoms. The low prevalence of chronic bronchitis among the farmers was especially surprising, since this symptom is probably most consistently found to be associated with farming [914]. One explanation for the current finding is that chronic bronchitis is especially associated with pig farming $[14,25,26]$ and very few farmers of the present study worked in piggeries. In addition, this study was restricted to females, whereas the previous studies showing the association between farming and chronic bronchitis have included either exclusively $[9,10]$ or predominantly [11-13] males.

In conclusion, although intensive and long-standing animal husbandry often induces upper airway symptoms, it may also reduce the risk of pet- and pollen-induced upper airway symptoms. These findings offer promise with respect to the increasing problem of allergic disorders worldwide by showing that the human immune system may also be flexible after early adulthood.

Acknowledgements. The authors would like to thank R-L. Väätäinen for help with the fieldwork.

\section{References}

1. Braun-Fahrlander C, Gassner M, Grize L, et al. Prevalence of hay fever and allergic sensitization in farmer's children and their peers living in the same rural community. SCARPOL team. Swiss Study on Childhood Allergy and Respiratory Symptoms with Respect to Air Pollution. Clin Exp Allergy 1999; 29: 28-34.

2. von Ehrenstein OS, von Mutius E, Illi S, Baumann L, Bohm O, von Kries R. Reduced risk of hay fever and asthma among children of farmers. Clin Exp Allergy 2000; 30: 187193.

3. Riedler J, Eder W, Oberfeld G, Schreuer M. Austrian children living on a farm have less hay fever, asthma and allergic sensitization. Clin Exp Allergy 2000; 30: 194-200.

4. Downs SH, Marks GB, Mitakakis TZ, Leuppi JD, Car NG, Peat JK. Having lived on a farm and protection against allergic diseases in Australia. Clin Exp Allergy 2001; 31: 570 575.

5. Ernst P, Cormier Y. Relative scarcity of asthma and atopy among rural adolescents raised on a farm. Am J Respir Crit Care Med 2000; 161: 1563-1566.

6. Kilpelainen M, Terho EO, Helenius H, Koskenvuo M. Farm environment in childhood prevents the development of allergies. Clin Exp Allergy 2000; 30: 201-208.

7. Leynaert B, Neukirch C, Jarvis D, Chinn S, Burney P, Neukirch F. Does living on a farm during childhood protect against asthma, allergic rhinitis, and atopy in adulthood? Am J Respir Crit Care Med 2001; 164: 1829-1834.

8. von Mutius E, Braun-Fahrlander C, Schierl R, et al. Exposure to endotoxin or other bacterial components might protect against the development of atopy. Clin Exp Allergy 2000; 30: 1230-1234.

9. Dosman JA, Graham BL, Hall D, van Loon P, Bhasin P, Froh F. Respiratory symptoms and pulmonary function in farmers. J Occup Med 1987; 29: 38-43.

10. Choudat D, Goehen M, Korobaeff M, Boulet A, Dewitte JD, Martin MH. Respiratory symptoms and bronchial reactivity among pig and dairy farmers. Scand $J$ Work Environ Health 1994; 20: 48-54.

11. Carvalheiro MF, Peterson Y, Rubenowitz E, Rylander R. Bronchial reactivity and work-related symptoms in farmers. Am J Ind Med 1995; 27: 65-74.

12. Terho EO, Koskenvuo M, Kaprio J. Atopy: a predisposing factor for chronic bronchitis in Finland. J Epidemiol Community Health 1995; 49: 296-298. 
13. Dalphin JC, Dubiez A, Monnet E, et al. Prevalence of asthma and respiratory symptoms in dairy farmers in the French province of the Doubs. Am J Respir Crit Care Med 1998; 158: 1493-1498.

14. Vogelzang PF, van der Gulden JW, Tielen MJ, Folgering H, van Schayck CP. Health-based selection for asthma, but not for chronic bronchitis, in pig farmers: an evidence-based hypothesis. Eur Respir J 1999; 13: 187-189.

15. Danuser B, Weber C, Kunzli N, Schindler C, Nowak D. Respiratory symptoms in Swiss farmers: an epidemiological study of risk factors. Am J Ind Med 2001; 39: 410-418.

16. Radon $\mathrm{K}$, Danuser $\mathrm{B}$, Iversen $\mathrm{M}$, et al. Respiratory symptoms in European animal farmers. Eur Respir J 2001; 17: 747-754.

17. Asher MI, Keil U, Anderson HR, et al. International Study of Asthma and Allergies in Childhood (ISAAC): rationale and methods. Eur Respir J 1995; 8: 483-491.

18. Rask-Andersen A. Inhalation fever. In: Harber P, Schenker M, Balmes J, eds. Occupational and Environmental Respiratory Disease. St Louis, Mosby-Year Book, 1995; pp. 243-258.

19. Simpson JC, Niven RM, Pickering CA, Fletcher AM, Oldham LA, Francis HM. Prevalence and predictors of work related respiratory symptoms in workers exposed to organic dusts. Occup Environ Med 1998; 55: 668-672.
20. Eduard W, Douwes J, Mehl R, Heederik D, Melbostad E. Short term exposure to airborne microbial agents during farm work: exposure-response relations with eye and respiratory symptoms. Occup Environ Med 2001; 58: 113118.

21. American Thoracic Society. Respiratory health hazards in agriculture. Am J Respir Crit Care Med 1998; 158: S1-S76.

22. Yabuhara A, Macaubas C, Prescott SL, et al. TH2-polarized immunological memory to inhalant allergens in atopics is established during infancy and early childhood. Clin Exp Allergy 1997; 27: 1261-1269.

23. Braun-Fahrlander $\mathrm{C}$. The role of the farm environment and animal contact for the development of asthma and allergies. Clin Exp Allergy 2001; 31: 1799-1803.

24. Thelin A, Hoglund S. Change of occupation and retirement among Swedish farmers and farm workers in relation to those in other occupations. A study of "elimination" from farming during the period 1970-1988. Soc Sci Med 1994; 38 $147-151$.

25. Iversen M, Dahl R, Korsgaard J, Hallas T, Jensen EJ. Respiratory symptoms in Danish farmers: an epidemiological study of risk factors. Thorax 1988; 43: 872-877.

26. Terho EO. Work-related respiratory disorders among Finnish farmers. Am J Ind Med 1990; 18: 269-272. 